\title{
Arbor
}

\section{¿Teología para agnósticos?}

\author{
Ignacio Sotelo Martínez
}

Arbor CLXXI, 676 (Abril), 819-832 pp.

Pretendo exponer de la manera más breve unas pocas razones que muestren que la teología concierne también al agnóstico. Por teología entiendo la reflexión sistemática en torno a la fe cristiana y por agnóstico, también en sentido muy amplio, aquel que no participa de esta fe. La tesis que defiendo es que no es necesaria la fe para interesarse por la teología; tiene sentido ocuparse de Dios sin creer en su existencia.

¿Por qué el agnóstico habría de ocuparse de la teología cuando el creyente parece que no la necesita? Cree antes de examinar reflexivamente su fe, que no depende de argumentos ni de demostraciones. Lo cierto es que la teología no conduce a la fe y hasta puede dudarse de si la fortalece. Conozco personas profundamente creyentes que huyen de las disquisiciones teológicas como de la peste. Viven la fe en una experiencia de amor al prójimo que no precisa de argumentos. Les basta acompañarse con las Sagradas Escrituras y de algunos libros piadosos o de espiritualidad. Cabría ampliar el horizonte de este artículo y preguntarse por el alcance y sentido que tenga la "reflexión sistemática» sobre Dios para aquellos que creen.

En todo caso, no deja de ser paradójico intentar una defensa de la teología, cuando parece que les sobra, tanto a agnósticos como a creyentes; incluso la Iglesia ha encerrado a los teólogos en un gueto en el que, si bien gozan de mucha mayor libertad que en el pasado, la disfrutan en buena parte porque se han quedado sin audiencia. Escriben exclusivamente para los colegas que son los únicos que los leen. Claro que, dada la fragmentación actual de los saberes, lo mismo les ocurre a los demás especialistas.

Si una buena parte de los creyentes se desentienden de la teología, ¿̇por qué habría de ocupar al agnóstico? Barrunto que una vindicación de la teología valga tanto para los unos como para los otros, pero en esta ocasión considero tan sólo las razones del interés que por la teología pueda tener el agnóstico, aunque quizá no sean muy distintas de las que podría tener el creyente. 


\section{Pensar a Dios sin creer en su existencia}

Claro que las cosas no fueron siempre así. Hubo un tiempo, justamente, en aquel en que se desarrolló la teología, en que la fe aspiraba a justificarse con argumentos, incluso a fundamentarse racionalmente. De ser considerada la reina de todas las ciencias - «la teología, por lo mismo que es la ciencia de Dios, es el océano que contiene y abarca todas las ciencias, así como Dios es el océano que contiene y abarca todas las cosas» al decir de nuestro Juan Donoso Cortés- se ha visto desplazada al desván de la historia. Veamos las razones por las que hemos de sacarla de la marginalidad en que se encuentra arrinconada.

Si nos interesamos por la teología, en primer lugar, es porque necesitamos conocer nuestro pasado, saber de dónde venimos. La cultura europea occidental a la que pertenecemos tuvo en la cristiandad latina su antecesora inmediata, y fue en esta época cuando, sobre todo a partir del siglo XII, la teología se desarrolló con especial ímpetu. Mirada retrospectiva que habría que ampliarla hasta dar cuenta de las formas en que la religiosidad cristiano-judaica se fusiona con la filosofía helenística en los primeros siglos de nuestra era, un capítulo fundamental de nuestra historia intelectual que no puede desconocer el creyente ni el escéptico que quiera hacerse cargo de su pasado común.

Parto, pues, del postulado de que, sin creer en su existencia, cabe muy bien intentar pensar la idea de Dios. Se trata, en cierto modo, de la inversión del famoso «argumento ontológico» de San Anselmo (1033-1109), según el cual la idea de Dios implicaría de por sí su existencia: si por definición Dios reúne todas las perfecciones, no le podría faltar la más esencial, la de existir; luego pensar a Dios incluye su existencia. San Anselmo en el Proslogium parte precisamente de rechazar lo que constituye mi postulado de partida: que «es distinto estar en la inteligencia que existir», proposición que considera propia del insensato que se atreve a negar a Dios. «Y, en verdad, el Ser que es tal que nada más grande puede pensarse, no puede estar en la sola inteligencia, pues si, efectivamente, estuviese en la sola inteligencia, se podría imaginar un ser como Él que existiese también en la realidad y que sería, por tanto, mayor que Él. Así que si estuviese sólo en la inteligencia el ser que es tal que nada mayor pueda ser pensado, sería tal que algo mayor que Él podría pensarse».

$\mathrm{El}$ argumento supone la visión platónica de las ideas como si existieran realmente. Hace mucho tiempo que ha perdido vigencia, a lo más tardar desde Kant; pero, ello no debe ser motivo para echarlo en el olvido. Conviene hacerse cargo tanto de la fuerza enorme que tuvo en el pasado -convierte la existencia de Dios en evidencia- como del papel central que 
este argumento ha desempeñado a la hora de fundamentar racionalmente la fe. San Anselmo recalca que «si no creéis, no comprenderéis», pero también que la fe busca y facilita la comprensión (fides quarens intellectum). Instalado sólidamente en la fe, es decir, en una situación como la vivida en la Edad Media, en que cualquier interpretación del mundo y de la sociedad remite siempre a Dios, resulta imposible dudar de la existencia de un Dios en el que todos creen y desde el que se explica y fundamenta todo lo existente. Si se percibe la realidad desde la fe, la realidad corrobora la fe. Si se cree en Dios, en todas partes se atisba su presencia. El conjunto de evidencias al que nos remite el argumento de San Anselmo es tan brillante como convincente dentro de sus premisas; conserva incluso cierta actualidad al poner de manifiesto los errores de una metafísica racional que vincula pensamiento y existencia como las dos caras de una misma moneda.

\section{Visión teológica versus visión científica}

En un largo proceso de racionalización que se inicia con la primera ilustración en la Grecia clásica, el politeísmo incuba el monoteísmo, y éste a su vez al ateísmo. En el helenismo, sin embargo, la ciencia natural no logra consolidarse, ni el ateísmo llega a sobrepasar pequeños círculos cercanos a determinadas escuelas filosóficas, quedando al final aplastado por las religiones orientales que terminan por aliarse con las filosofías teístas. Proceso que de alguna forma se repite en la modernidad, una ilustración que desarrolla un monoteísmo racional que también desemboca en el ateísmo, pero esta vez la ciencia sí logra afianzarse, gracias en buena parte a su aplicación técnica, con lo que se crea la base material para que se expanda el ateísmo que lleva en su seno. La ciencia moderna es atea en el sentido de que no precisa, antes al contrario, rechaza la idea de Dios para explicar lo existente (la naturaleza y el hombre). Laplace da a Napoleón una respuesta contundente sobre el papel de Dios: «Señor, no preciso esta hipótesis». Lo propio del hacer científico es que por principio rehúsa acudir a Dios, como explicación cercana o lejana. Actitud propia de una ciencia que va arrebatando, paso a paso, zonas que se habían considerado más allá de su alcance, como el origen de la vida a partir de lo inerte, o las redes neuronales para dar cuenta del espíritu humano.

Una vez que ha quedado arrumbado un argumento de tanta finura intelectual como el ontológico, todos los demás que tratan de demostrar la existencia de Dios partiendo de la creación -el mundo y el hombre- en la 
que estaría grabada la huella del Creador, se diluyen como azucarillos en el café. El afán de fundamentar racionalmente la fe, lleva ya en su entraña, tanto la posibilidad de un desarrollo científico, como el ateísmo futuro. En el empeño de fundamentar de manera racional la fe subyace ya en embrión la ciencia moderna que, justamente, es la que da el tiro de gracia, si no a la creencia en Dios, sí por lo menos a la forma medieval de vincular razón y fe.

Cosmos, hombre y Dios, forman el trípode sobre el que se asienta la visión cristiana de la realidad. Conviene partir de esta tríada para seguir los vericuetos por los que se ha ido evaporando «la hipótesis de Dios», de modo que en la modernidad nos quedamos sólo con dos sustancias, hombre y mundo. A mitad del XIX, al resultar patente que el hombre proviene de la naturaleza, sin que nos distingamos de los demás seres vivientes, de cuya evolución formamos parte, se disuelven incluso las diferencias entre hombre y naturaleza. De tres pasamos a una sola sustancia, o si se quiere, de una concepción teológica a una científica de la realidad.

Necesitamos la teología como punto de partida para entender el proceso que nos lleva a la situación actual. Pero no basta con describir el punto de partida y el de llegada; no basta con contraponer una visión teocéntrica con una científica de la realidad, tirando la primera por la borda y asumiendo la segunda con todas sus consecuencias. La insatisfacción ante semejante comportamiento proviene de que se ha desplomado la idea lineal de progreso, basada en una predilección continua de lo nuevo, como si fuese siempre mejor que lo anterior. Frente al dogma progresista de que lo nuevo supera siempre a lo viejo, hoy nos inclinamos a dar la razón al proverbio ruso que dice que nada es tan bueno que no comporte algo negativo, ni nada tan malo que no tenga algo positivo. Ello complica mucho el proceso histórico que se revela bastante más complejo de lo que supone una idea lineal de progreso. En vez de dar por sentado que lo nuevo es siempre mejor que lo que le precede, se impone una visión que registre en lo nuevo, además de los elementos positivos, los negativos, de modo que quede de manifiesto los altos costos que a veces pagamos por los pretendidos avances.

Desde esta nueva visión del proceso histórico, no linealmente ascendente, ahora sabemos que en el camino hemos ido perdiendo cantidad de dimensiones de las que alguna tal vez hubiere importado conservar. Desde luego que no podemos detener el curso de la historia, como quiere el reaccionario impotente; pero tampoco nos está permitido echar a la basura todo lo que parece que se ha quedado viejo, como quiere el progresista incontinente. Nada más destructor que una idea del progreso que, 
sin preguntarse por los costos de las innovaciones, va abandonando cadáveres en la cuneta. Así como algunos, conscientes de lo perdido en el cambio, hemos tratado de recuperar la visión del mundo politeísta, propia de la cultura grecolatina, que desplazó el cristianismo, tampoco estamos dispuestos a deshacernos de la visión cristiana sin examinar con algún detenimiento los costos que conlleva el abandonarla. Operación que obliga a mantenerse en contacto con la teología que, justamente, ha elaborado una buena cantidad de los materiales perdidos.

\section{Saber y creer}

La idea del hombre y del cosmos que tenía el cristiano provenía ciertamente de lo revelado por Dios, pero también de los conocimientos «científicos» de cada época, hasta el punto de que la teología se constituye como reflexión sobre la manera como se relacionan creer y saber, cuestión que, pese a que está bastante marginada en la teología de nuestros días, me parece tan fundamental, como lo fue en épocas anteriores. El acuerdo del que se partía, y del que creo se sigue partiendo, es que la idea del hombre y del mundo que nos proporciona la Revelación tendría de algún modo que coincidir con las que vamos ganando con la razón, la observación, o la experimentación del mundo. Coincidencia que ya explicita claramente San Agustín cuando dice que «la verdadera filosofía es religión verdadera y, recíprocamente, la religión verdadera es verdadera filosofía». En definitiva, lo que nos enseña el conocimiento humano no puede estar en contradicción con las verdades reveladas. Si surgiese algún desajuste, sería debido, desde la perspectiva del teólogo, a que la ciencia se extralimita en sacar conclusiones que no le corresponde.

En la relación de creer y saber caben, en principio, tres posiciones, que son las que, de hecho, nos encontramos. La primera, a la que llamaré tesis, sostiene la diferencia absoluta entre fe y razón. El saber humano, siempre falible y provisional, nada tendría que aportar a lo que conocemos con la certeza plena de lo revelado por Dios. La antítesis, al contrario, afirma que la razón es una vía adecuada para conocer y fundamentar lo que creemos por la fe. Y una tercera posición intermedia mantiene que la razón puede conocer y fundamentar verdades conocidas por la Revelación, como por ejemplo la existencia de Dios, a la vez que tiene su tope en algunas verdades sobrenaturales que escapan a la razón y que sólo conocemos por la Revelación, como la Trinidad.

La primera posición separa pulcramente creer y saber, fe y razón. Está presente desde la patrística hasta nuestros días. Un buen repre- 
sentante podría ser el tan extremoso Tertuliano que llega a decir que la muerte del Hijo de Dios es digna de fe, justamente, porque para el sentido común no es creíble: ¿cómo podría morir Dios? Asimismo la Resurrección es cierta, porque resulta inconcebible. Aunque la formula credo quia absurdum parece que no se encuentra en sus escritos, expresa muy bien la síntesis última de su pensamiento. Opinión que, más matizada, comparte el obispo de Lyon, San Ireneo, para el que el único conocimiento del que podemos estar plenamente seguros es el que proviene de la Revelación. Oponiéndose a la ola racionalista del siglo XIII, renace un fideísmo -llamo así a postular la primacía exclusiva de la fe-que denuncia a la filosofía, no sólo, como superflua a la hora de conocer las verdades reveladas, sino incluso muy peligrosa, ya que la mayor parte de las herejías provendrían, justamente, de la intromisión de la razón en el campo de las verdades reveladas. En este contexto parece decisiva la posición de Guillermo de Occam, que no considera concluyentes, aunque sí verosímiles, las demostraciones racionales de la existencia de Dios. No habría modo de fundamentar racionalmente la fe, por lo que habría que abandonar los argumentos equívocos de la razón y basarla exclusivamente en las Sagradas Escrituras. Lutero se confesó «de la escuela de Occam». Desde un fideísmo extremo, el reformador alemán llama a la razón, no ya sólo «enemiga de la fe», sino incluso "prostituta del diablo», con lo que Aristóteles resultaba «el impío defensor de los papistas».

La fe surge de una experiencia interna que lleva al asentimiento de las Sagradas Escrituras como palabra de Dios. En suma, al separar limpiamente creer y saber, la fe se refugia en un "castillo inexpugnable» ante los ataques de la ciencia, sea cual fuere su contenido en cada época. La creencia se movería en un plano sobrenatural, inalcanzable al conocimiento humano, en el que los argumentos racionales carecen de sentido, de modo que entre creer y saber no podría surgir contradicción alguna. $\mathrm{Si}$ el saber no influye en absoluto sobre lo que se cree, poco importa entonces los dictámenes de la ciencia. De ahí que el fideísmo sea la respuesta que se adapta mejor a la revolución científica de la modernidad.

La segunda posición da por descontado que la razón sirve para esclarecer tanto las verdades naturales, como las sobrenaturales. También lo revelado por Dios estaría sometido a la razón. Toma fuerza con la revolución racionalista del siglo XIII, antecedente inmediato del racionalismo que acabará por imponerse en la modernidad. Es una línea que puede seguirse desde Pedro Abelardo hasta el mallorquín Ramón Llull y el barcelonés Raimundo de Sabunde. Nuestro Ramón Llull estaba plenamente convencido de que la realidad es racional y, por tanto, el saber uno. Al hacer interdependientes lógica y ontología, se revela el más moderno de los 
modernos, precursor directo de Leibniz y de Hegel. Si se identifica creer con saber, entonces cabria convencer a los infieles, musulmanes y judíos, de la verdad científica del cristianismo. ¿Qué mejor fundamento del cristianismo que demostrar científicamente la verdad de la Trinidad y de la Encarnación! «El entendimiento es semejante a un hombre que sube con dos pies por una escalera. En el primer escalón pone el pie de la fe y luego el del entendimiento, cuando el pie de la fe está en el segundo, y así va subiendo. El fin del entendimiento no es creer, sino entender (credere non est finis intellectus, sed intelligere), pero se sirve de la fe como instrumento». Valdría la pena comentar con algún detalle eso de que «el fin del intelecto no es creer, sino entender» que encontramos en Ars Magna de Llull. En este punto Raimundo de Sabunde se muestra fiel discípulo del mallorquín. Según nos cuenta Montaigne «su fin es audaz y valeroso, ya que procura con razones humanas y naturales, establecer y demostrar contra los ateos todos los artículos de la religión cristiana». Valdría la pena tratar de dilucidar por qué, al ocaso de la Edad Media, fueron dos españoles del reino de Aragón los representantes más conspicuos del racionalismo - ¿acaso la influencia islámica?-, preeminencia que perdimos en los siglos siguientes: ¿debido a la Inquisición con todo lo que representa?

Aunque Tomás de Aquino considerase absurda tamaña pretensión, estaba también convencido de que las verdades de la fe contaban con una cierta plausibilidad, hasta el punto de que si no eran racionalmente demostrables, por lo menos parecían razonables. Esta tercera posición intermedia supone que la razón tiene acceso a las verdades reveladas, pero no a todas. Es decir, no existe una ruptura clara entre creer y saber, pero tampoco la creencia se agota en el saber, siempre provisional y limitado. Tomás de Aquino distingue saber de creer, según el grado con que el sujeto asiente. Si ante una proposición cabe la duda, es que se trata de una mera opinión; si se muestra evidente, entonces es ciencia; si conlleva una certeza absoluta sin mostrar evidencia, es que pertenece a la fe, que se sostiene en un fuerte asentimiento de la voluntad. La razón nos lleva hasta el umbral de la fe, praeambula fidei, pero para entrar en ella es menester que nuestra voluntad asienta, dispuestos a aceptar lo que Dios nos revele, acto para el que contamos siempre con la gracia divina.

Que la razón se haya introducido en la visión religiosa del mundo es uno de los caracteres privativos de la Europa cristiana. En el Islam, donde el racionalismo surgió antes, también impulsado por la filosofía griega, no terminó por fraguar; demasiado pronto desembocó en el ateísmo. Todavía en el siglo XII la teología cristiana estaba muy distante de una sistematización que aspirase a ser ciencia. Para exponer el dogma se contentaba con reunir textos sacados de las Escrituras y de los Santos Pa- 
dres. Una colección muy conocida que se empleó en la enseñanza fueron las Sentencias de Pedro Lombardo. Santo Tomás se puso a escribir la Suma Teológica, convencido de que estas colecciones no servían para «la enseñanza de los principiantes». Había que sistematizar la doctrina, fundamentándola racionalmente en lo que fuere posible. Aquí yace el carácter revolucionario de esta obra: ofrecer una visión razonable de todo lo existente, desde el comienzo hasta el final de los tiempos. En este sentido la Suma quiere ser un tratado científico, y lo es plenamente, si por ciencia entendemos la sistematización de conocimientos extraídos de principios que «son evidentes por sí mismos o se reducen a lo conocido en otra ciencia superior». Santo Tomás se pregunta si desde estos criterios la «doctrina sagrada» puede ser considerada ciencia y su respuesta es afirmativa, distinguiendo las ciencias que proceden de principios conocidos con la luz natural del entendimiento, siempre falibles, de aquellas que proceden de principios revelados por Dios y, por tanto, absolutamente ciertos. Una vez que ha demostrado racionalmente la existencia de Dios - las famosas cinco vías- no hay modo de negar el valor científico, es decir, de conocimiento verdadero, a todo aquello que Dios ha querido revelarnos. En ultimo término, la ciencia así entendida se descubre un saber racional que vincula y unifica todo lo existente en y por Dios. Tomás de Aquino constituye sin duda uno de los eslabones principales que enlazan el racionalismo griego con el moderno.

Difícilmente cabe encontrar mayor claridad y poder de convicción que en la Suma. Partiendo de la demostración de la existencia de Dios, de las cualidades de Dios a las que se puede llegar por la razón, los límites que tiene el entendimiento creado para alcanzar la esencia de Dios, sigue el Dios trinitario que se nos ha revelado más allá de la razón. La creación divina da cuenta de todo lo existente: las criaturas simplemente espirituales, los ángeles; aquéllas sólo corporales -minerales, plantas y animales- cuyo conjunto supone una descripción detallada de los seis días de la creación. En fin, el hombre, compuesto de cuerpo y espíritu, lo que le otorga un puesto muy especial en la creación. La naturaleza, formada tan sólo de cuerpos, aunque con distintas propiedades, se completa con el hombre, cuerpo y espíritu, y con él comienza la historia. Paraíso terrenal, caída y expulsión; elección de un pueblo para que de él naciera el Redentor. Encarnación y nacimiento, vida y enseñanza, pasión y muerte en la cruz. La resurrección y ascensión a los cielos del Hijo de Dios constituyen el eje universal de la historia, que acaba con su vuelta triunfante en el Juicio Final. Desde la creación hasta el final de los tiempos, la historia, al igual que el destino de cada persona, es un proceso que viene de Dios y se dirige a Dios. 


\section{¿Teología para agnósticos?}

$\mathrm{El}$ antecedente inmediato a nuestra visión moderna del hombre y del mundo es la concepción teocéntrica que de manera tan admirable sistematizó Santo Tomás. Es menester partir de ella para dar cuenta de las ideas que hoy tenemos del hombre y del mundo. Han ido desgajándose, rama a rama, de esta visión. Me importa recalcar algo que debería ser obvio, pero que está bastante olvidado: el racionalismo escolástico, incluido el tomista, está en el origen de la visión científica del hombre y del universo que cuaja en la modernidad. El racionalismo, implícito en la Suma, unifica saber y creer. En un primer momento una fe que se cree fundada en la razón, o por lo menos razonable, adquiere una fuerza inmensa; pero, cuando se desploma la demostración racional de la existencia de Dios, queda de manifiesto toda su fragilidad. El intento de fundamentar la fe en la razón acaba con el desmoronamiento de la fe.

\section{La permanencia desfasada del tomismo}

Pese a que la obra de Santo Tomás asombre, tanto por la extensión de sus conocimientos, y sobre todo por el sentido común que pone de manifiesto, como por el ingenio de que da prueba al acoplar la filosofía aristotélica a las necesidades de la doctrina cristiana, a nadie puede chocar que, habiendo sido tantas y de tal calado las innovaciones, una buena parte de la teología de su tiempo las recibiese con enorme recelo, cuando no duras criticas. Haber introducido una filosofía extraña en la explicación de la doctrina sagrada tenía que parecer a muchos una profanación, o algo peor, una aventura peligrosísima que no se sabía en qué podía acabar. En efecto, en cuanto se independiza la razón, ya no se la puede controlar. Al hundirse la ilusión de que la fe podría fundamentarse racionalmente, deja como poso tan sólo el deseo pío de que al menos parezca razonable. Y esto ya es cuestión opinable. Puede ocurrir que lo que al creyente le parece razonable, al incrédulo, en absoluto.

Renuncio a discutir, aunque no a formular, dos cuestiones que, si pudiéramos ocuparnos de ellas con algún detenimiento, nos ayudarían bastante en el tema que tratamos. La primera reza: ¿por qué, pese al rechazo inicial, se aceptó enseguida la teología «científica» de Santo Tomás?; ¿por qué el racionalismo tomista contó desde muy pronto con el apoyo de la Iglesia jerárquica? La segunda traslada esta misma cuestión a una situación por completo distinta, aquella que se presenta después de que la ciencia moderna hubiese sustituido al aristotelismo, incluso tras la secularización ilustrada y la conmoción revolucionaria del siglo XVIII. ¿Cómo se explica que renaciese el tomismo en la primera mitad del XIX, apro- 
vechando la Iglesia, o al menos favoreciendo, el intento imposible de restaurar la unidad del trono y del altar que había caracterizado a la sociedad estamental del «antiguo régimen»? En rigor, el triunfo indiscutido del tomismo, pese a haber estado en alza desde la contrarreforma, es de fecha bastante reciente, si se quiere, desde 1879 con la encíclica Aeterni Patris de León XIII, valoración que sigue subiendo con los tres Píos, Pío X, Pío XI y Pío XII.

Si pudiéramos profundizar en estas dos cuestiones, triunfo inmediato del tomismo y sorprendente renacimiento en el siglo XIX, tal vez estaríamos en condiciones de explicar por qué el cristianismo habría encajado tan perfectamente en la sociedad estamental que establece abismales diferencias a partir del nacimiento. ¿Cómo pudo acoplarse el cristianismo a la esclavitud en el mundo antiguo y al feudalismo en la cristiandad, cuando la esencia del mensaje de Jesús es la igualdad de todos los humanos, en cuanto hijos de Dios? Una buena noticia que, claro está, alegra a los pobres y desposeídos, pero mucho menos a los ricos y poderosos. ¿Cómo un mensaje de fraternidad pudo arraigar en sociedades que marcaban tan enormes diferencias sociales? Como se ve, cuestiones esenciales del desarrollo social y político de Europa no pueden plantearse sin la correspondiente conexión con la teología.

\section{La ruptura moderna con la teología}

Hemos comprobado que no cabe hacerse cargo del pasado sin plantear cuestiones que exigen un conocimiento amplio de la teología y que la ciencia moderna proviene del racionalismo que se incrusta en la teología. Para entender su origen en la modernidad, es indispensable un conocimiento detallado de la conversión de la teología en filosofía, si se quiere, el trecho que va de Tomás de Aquino a Descartes. Ahora bien, el filósofo francés que inaugura la modernidad, sin dudar de su fe, rompe radicalmente con la teología, al recalcar que lo importante es "ganar el cielo», y para ello no se precisa de teologías. Sabe que «el camino no está menos abierto a los más ignorantes que a los más sabios y que las verdades reveladas que allí conducen están por encima de nuestra inteligencia, y no hubiese osado someterlas a la debilidad de mis razonamientos, ya que pensaba que para tratar de examinarlas con éxito, era preciso tener una ayuda extraordinaria del cielo y ser más que un hombre». La crítica de la teología no puede ser más contundente: no sirve para lo que de verdad importa, salvarnos y gozar a Dios en la otra vida, y además es una pretensión imposible, que supera la condición humana. De ahí que la fe que 
garantiza una vida virtuosa vaya por un lado y, por otro, la razón que exige un conocimiento evidente, tal como se descubre en el saber matemático. La modernidad cartesiana convierte a la teología en un saber superfluo -de nada sirve en el negocio de la salvación-, a la vez que uno imposible: la criatura finita no puede pensar a Dios. El ciclo de la teología habría llegado a su final.

Sin contar con la fe cristiana y la actuación de la Iglesia, nuestra historia resulta incomprensible. Nadie pone en duda la importancia de la teología para comprender nuestro pasado; se precisa tanto como la mitología para entender el mundo antiguo. La cuestión es saber de qué sirve la teología tras haber recorrido el trecho que va desde la separación cartesiana al ateísmo ilustrado. ¿Por qué convendría conectar de nuevo con la teología, una vez desaparecida de nuestro horizonte cognoscitivo que lo enmarca la ciencia?

Ante el ateísmo implícito en la ciencia, al creyente no le queda otro remedio que retrotraerse a otras esferas de conocimiento y dar por supuesto que el conocimiento científico no es el único; que cabe, en principio, imaginar realidades más allá del mundo sensible. La creencia se ha hecho compatible con la ciencia, pero al precio de una nítida separación del mundo que investiga la ciencia y el que proclama la fe. La grandeza de la fe medieval radicaba en que ponía en relación fe y razón, creencia y saber, pero el intento de fundamentar racionalmente la fe ha desembocado en el ateísmo. El ateo debería estar interesado en conocer sus antecedentes teístas, para así poder explicarse mejor su ateísmo, que hoy parece dominante, aunque no se sepa cuanto va a durar esta preeminencia.

\section{Dios más allá de la razón}

Ortega, subido al palo mayor en su función de vigía de la nación, en noviembre de 1926 -durante la dictadura de Primo de Rivera, importa la circunstancia- llegó a gritar un «Dios a la vista». No en el sentido de una vuelta a la religión, -precisamente de lo que se queja es de ese afán de identificar a Dios con las religiones- sino para recordar algo que se olvida demasiado a menudo, que «Dios es también un asunto profano». El Dios conceptual de la filosofía que vislumbra Ortega nos impone una reflexión que, en último término, cuestiona lo tangible como la ultima dimensión de la realidad. $\mathrm{El}$ «Dios a la vista» orteguiano es un aviso de que no podemos permanecer satisfechos en un positivismo cientificista. La ciencia es atea, sin duda; y así debe ser; pero el cientificismo, es decir, la reducción de todos los conocimientos al científico, no parece asumible sin más. Ortega no 
hace un alegato a favor de la existencia de Dios; únicamente se muestra en desacuerdo a que tiremos por la borda la noción de Dios, porque sirve de acicate para seguir buscando formas de conocimiento que sobrepasen el marco impuesto por la ciencia. Mantener la idea de Dios deja abierto un gran interrogante que no hay por qué cerrar precipitadamente. El que de la ciencia hayamos eliminado el concepto de Dios no debería implicar que de antemano lo eliminemos también de otras formas cognoscitivas posibles de construir la realidad. El concepto de Dios sirve al menos para librarnos de un cientificismo demasiado ramplón.

Todas las contradicciones de lo humano, su miseria y su grandeza, se reflejan en las muy distintas ideas que a lo largo de los milenios hemos ido construyendo de Dios. Se comprende que no podamos arrojarlas al olvido sin perder la memoria del largo camino recorrido para llegar a ser lo que somos. Necesitamos indagar la idea de Dios, de entrada, para averiguar el largo proceso de nuestro devenir, pero también para imaginar lo que todavía podríamos llegar a ser. La invención de Dios ha ayudado al hombre a elevarse más allá del reino animal. Nos hemos creído emparentados con los dioses. Dios nos habría hecho reyes de todo lo creado, creación que el sexto día habría culminado justamente con la del hombre. De ser criaturas de Dios provienen la dignidad, la libertad y la igualdad de los humanos. Claro que hoy podemos desligarlas de su origen divino y defenderlas por sí mismas, pero ello no quita que hayan ido granando, impulsadas por la idea de Dios. Por eso, decía, hay que tener mucho cuidado cuando desechamos esta idea; se podría llevar consigo cosas muy valiosas.

Ocuparnos de la idea de Dios sirve, no sólo para recuperar la memoria de nuestro pasado, sin la que no podemos comprendernos, sino también para poder romper moldes en el momento presente, escapando de los tópicos dominantes. El saber en cuanto se enroca termina por convertirse en escolástica. La de hoy, tengámoslo muy presente, es el ateísmo cientificista. De ahí que suponga un ejercicio saludable tratar de escapar del ateísmo, aunque no lo consigamos, así como en el siglo XVIII, cuando la razón y la ciencia empezaban abrirse camino, defender el ateísmo fue tan útil como benemérito. Cuando, como sucede ahora, ambas dominan con un poder absoluto, la reacción saludable podría ser adentrarse un poco en la selva de las ideas de Dios. Tiene la ventaja de que aviva la fantasía y con ella surte lo que más escasea en nuestro mundo, razones para la esperanza, que nunca pueden desprenderse de lo real -lo fáctico no puede albergar esperanza alguna- sino que hay que inventarlas. La teología es ciertamente un capítulo de la literatura fantástica, pero creo que Borges lo dijo en su honor, no para desacreditarla. 


\section{Filosofía y teología, una diferenciación imposible}

Un tema bastante peliagudo del que no se puede librar el filósofo es el deslinde claro de la teología, complejo mundo del que, al fin y al cabo, proviene la filosofía. El neopositivismo de la escuela de Viena en los años sesenta se abría paso en Colonia, representado por el entonces privatdozent Hans Albert. Hijo, si no recuerdo mal, de un pastor protestante, llevaba la voz cantante en el afán de limpiar el saber de cualquier conexión con la teología o la creencia. Los que no estábamos dispuestos a aceptar todas las reducciones que imponían los neopositivistas -que, además, por asumir sin la menor critica el orden económico-social establecido, resultaban harto sospechosas- y leíamos a Hegel y a Husserl, como era mi caso, preparando una tesis sobre Sartre -su ateísmo me parecía obvio, dicho sea de paso- éramos acusados de teólogos encubiertos, lo que a la postre, me obligaba a tratar de trazar las fronteras entre teología y filosofía de otra manera que el neopositivismo. Ello me llevó a leer a algunos teólogos, entre ellos a Karl Barth.

Para introducirme en una temática, para mí tan extraña como alejada, empecé por leer la teología protestante en el siglo XIX. Dos enseñanzas me han quedado en el recuerdo. La primera, que para adentrarse en la teología no era preciso pertenecer al gremio, sino tan sólo sentirse atraído por estas cuestiones, interés que no excluye, antes al contrario, «una postura critica, de negación o de escepticismo dentro de la teología o incluso contra la teología». El único que no tiene cabida «no es el teólogo que se equivoca, ni siquiera el adversario de la teología -no se puede ser adversario de la teología sin llegar a ser de alguna manera teólogosino el espectador ocioso que cree poder ver o hablar de algo que no le concierne». Para Barth, el único que queda fuera es el indiferente. Cabría muy bien una «teología para agnósticos», pero no, una para indiferentes.

La segunda enseñanza consiste en algo bastante obvio, pero que a mí se me reveló como nuevo, y es la estrecha vinculación de la filosofía con la teología, hasta el punto de que resulta imposible hacer una historia de la filosofía sin sus implicaciones teológicas, así como una de la teología sin sus concomitancias filosóficas. Se puede muy bien dar la espalda a la teología desde las ciencias naturales, pero no cabe hacerlo desde la filosofía. Barth dedica más de la mitad del libro a los prolegómenos de la teología decimonónica, y se ocupa de Rousseau, Lessing, Kant, Herder, Novalis y Hegel. Cuando se centra en la teología, parte de Schleiermacher, el teólogo más importante del siglo XIX que, al decir de Barth, pretendió serlo cabalmente, sin dejar por ello de ser hombre moderno, abierto a la filosofía y a la ciencia de su tiempo. Pronto caí en la cuenta que sin 
Schleiermacher no cabía entender el idealismo alemán; pero una vez metido en estos andurriales, era difícil mantener mi anterior desprecio por la teología.

Me llamó aún más la atención que entre los teólogos del XIX, Barth se ocupase de Ludwig Feuerbach, que había reducido la teología a antropología, y de David Friedrich Strauss, de menos fuste, pero muy digno de mención por su Vida de Jesús. La filosofía no puede renunciar a trazar una línea divisoria clara con la teología, pero al moverse en un terreno tan movedizo como es la frontera entre ambas, a poco que intente cumplir con su misión de enfrentarse a las cuestiones capitales que nos conciernen, no puede evitar invadir su territorio. Si se quiere romper de plano con la teología, previamente hay que haber roto con la filosofía. El rechazo de la teología sólo resulta congruente si, como hizo el positivismo, incluye el de la filosofía.

En fin, la lectura de las obras teológicas nos ofrece la oportunidad de ocuparnos de temas que estimo importantes, pero que, al faltar las plataformas o los canales de comunicación apropiados para ocuparse de estas cuestiones, difícilmente cabe debatir en publico. En nuestras sociedades por completo secularizadas no está bien hablar en público de religión, como tampoco lo está el referirse a la vida sexual de cada uno. Es obsceno mostrar la intimidad, sea ésta religiosa o sexual. En la universidad se estudia todo lo que concierne al cosmos y al hombre, eludiendo, eso sí, las concomitancias religiosas. De religión no se habla más que en las cátedras de teología y en las de filosofía o historia de las religiones. En una España en la que el nacionalcatolicismo ha dejado huellas tan profundas, importa que nuestros ateos se acerquen un poco a las distintas tradiciones religiosas, sin las que no cabe comprender el pasado -y sin él, nada se entiende del presente- pero también que los creyentes, chapados a la antigua, descubran que los incrédulos tienen sus razones para mantenerse en la increencia, sin por eso ser especialmente desgraciados o malas personas. 